\title{
Central ghrelin production does not substantially contribute to systemic ghrelin concentrations: a study in two subjects with active acromegaly
}

Fanny M van der Toorn, Joop A M J L Janssen, Wouter W de Herder, Fabio Broglio ${ }^{1}$, Ezio Ghigo ${ }^{1}$ and Aart J van der Lely

Department of Internal Medicine, Section of Endocrinology, Erasmus MC, PO Box 2040, 3000 CA Rotterdam, The Netherlands and ${ }^{1}$ Department of Internal Medicine, Division of Endocrinology and Metabolism, Ospedale Molinette, University of Turin, C so Dogliotto, 10126 Turin, Italy

(Correspondence should be addressed to A J van der Lely; Email: vanderlely@inw3.azr.nl)

\begin{abstract}
Introduction: In an animal model of acromegaly (PEPCK-hGH transgenic mice), low systemic levels of ghrelin have been observed compared with normal mice. We hypothesized that systemic circulating ghrelin levels are also decreased in humans with active acromegaly and that the contribution of central ghrelin production to systemic ghrelin levels is minimal.

Objectives: The aim of the present study was to investigate, in two subjects with active acromegaly, whether there are differences between systemic ghrelin levels and ghrelin concentrations in the petrosal sinus.

Design: We measured systemic and central ghrelin levels in these two acromegalic patients by bilateral simultaneous inferior petrosal sinus sampling. Central and systemic blood samples were drawn before and $1,5,10,15$ and $20 \mathrm{~min}$ after stimulation with GH-releasing hormone (GHRH). Ghrelin was measured with a commercially available radioimmunoassay.

Results: In one acromegalic subject, the baseline systemic and central ghrelin levels were within the same range as in two non-acromegalic obese subjects. No gradient could be observed between central and systemic ghrelin concentrations. Stimulation with GHRH did not change the ghrelin concentrations in this patient. In the other acromegalic subject, the systemic ghrelin levels were also in the same range as in two non-acromegalic obese subjects. However, in this subject, baseline ghrelin concentrations in the right inferior petrosal vein were considerably lower than the systemic ghrelin concentrations, indicating a peripheral over central gradient. Administration of GHRH induced a significant rise in central ghrelin concentrations in the right inferior petrosal vein. Ghrelin levels in the left inferior petrosal vein and systemic ghrelin levels were in the normal range and GHRH stimulation did not change these concentrations.

Conclusions: The absence of a central over peripheral ghrelin gradient in these two acromegalics indicated that circulating ghrelin is mainly produced peripherally. Circulating systemic ghrelin levels were not decreased in these two subjects with active acromegaly.
\end{abstract}

European Journal of Endocrinology 147 195-199

\section{Introduction}

For years, regulation of growth hormone (GH) release was considered to be the net result of stimulation by GH-releasisng hormone (GHRH) and inhibition by somatostatin. The discovery of ghrelin, a 28 amino acid peptide, which induces GH release in vivo and in vitro, has added another regulatory mechanism to this system (1). Ghrelin is a more potent GH secretagogue than GHRH (2). The observation that ghrelin and GHRH act synergistically suggests that these peptides have, at least partially, different mechanisms of action. However, the feedback mechanisms of ghrelin are still unknown (2). Ghrelin is produced in the stomach and is also expressed in the hypothalamic arcuate nucleus (1). Korbonits and co-workers detected ghrelin mRNA expression in normal human pituitary tissue as well as in pituitary adenomas, including somatotroph adenomas. This strongly suggests that ghrelin is produced in the pituitary gland, where it may influence the release of $\mathrm{GH}$ in an autocrine or paracrine manner $(3,4)$.

In a murine model of acromegaly (PEPCK-hGH transgenic mice), low levels of systemic ghrelin have been observed as compared with controls (5). We hypothesized that systemic ghrelin levels are also 
decreased in humans with active acromegaly and that the contribution of central ghrelin production to the systemic ghrelin levels is minimal. The aim of the present study was to investigate whether there are differences between systemic ghrelin levels and ghrelin concentrations in the petrosal sinus in human acromegaly. Therefore, we measured systemic and central ghrelin levels in two acromegalic patients, who underwent bilateral simultaneous inferior petrosal sinus sampling (BSIPSS) because of diagnostic reasons.

\section{Patients and methods}

\section{Patients and controls}

Two males with active acromegaly were studied and two obese subjects without acromegaly were studied as controls. However, the body mass index (BMI) of the obese subjects $\left(31.0\right.$ and $\left.32.1 \mathrm{~kg} / \mathrm{m}^{2}\right)$ was lower that the BMI of the two acromegalics (39.2 and $34.7 \mathrm{~kg} / \mathrm{m}^{2}$ ). Both acromegalic patients (56 and 51 years) presented with classical acromegalic complaints. Physical examination revealed typical acromegalic features. Serum insulin-like growth factor-I (IGF-I) levels were significantly elevated: $105 \mathrm{nmol} / \mathrm{l}$ in patient 1 and $65 \mathrm{nmol} / \mathrm{l}$ in patient 2 (normal range for age and gender: $11-35 \mathrm{nmol} / \mathrm{l})$. Fasting insulin concentrations in these two acromegalics were 14.9 and $6.4 \mathrm{mU} / \mathrm{l}$ respectively. The diagnosis of acromegaly was confirmed in both patients by an abnormal GH response to an oral glucose tolerance load $(\mathrm{GH}>2.5 \mu \mathrm{g} / \mathrm{l})$. As these acromegalic subjects initially showed no clear pituitary abnormalities on magnetic resonance imaging (MRI) at the referring hospital, we performed BSIPSS in both subjects, at their request, to locate an adenoma. However, in the first acromegalic patient, a somatotroph pituitary adenoma of $7 \mathrm{~mm}$ at the right side of the pituitary could be detected by MRI at follow-up. He showed normalization in serum IGF-I after initiation of long-acting somatostatin analogue therapy as primary treatment. Also, in the second acromegalic patient, a centrally located somatotroph microadenoma was found with a diameter of $1 \mathrm{~cm}$ during follow-up MRI. He successfully underwent trans-sphenoidal surgery.

Two patients with centripetal obesity (one 70-yearold male and one 42-year-old female) underwent BSIPSS because of suspected Cushing's disease as part of the diagnostic work-up. Fasting insulin concentrations in these two non-acromegalic obese subjects were 29.9 and $34.6 \mathrm{mU} / \mathrm{l}$ respectively. However, after extensive testing, Cushing's syndrome could be excluded in both subjects. Cushingoid obesity was diagnosed in the male subject while polycystic ovary syndrome was diagnosed in the female subject. We therefore decided to use both of them as controls for this study. The study was performed according to the rules of the hospital medical ethics committee. All subjects entered the study after informed consent.

\section{BSIPSS}

After an overnight fast, BSIPSS was performed via bilateral femoral vein puncture. In both inferior petrosal sinuses, a 4 French multipurpose catheter (Cordis Europe, Roden, The Netherlands) was installed and catheter position was checked by injecting small amounts of iodinated non-ionic contrast (6). Central and peripheral blood samples were drawn before and $1,5,10,15$ and $20 \mathrm{~min}$ after stimulation. Control subjects were stimulated with $1 \mu \mathrm{g} / \mathrm{kg}$ body weight corticotrophin-releasing hormone (CRH; Ferring, Hoofddorp, The Netherlands). The acromegalic patients were stimulated with recombinant human GHRH (Ferring) as an intravenous bolus injection $(1 \mu \mathrm{g} / \mathrm{kg})$.

\section{Biochemical measurements}

All blood samples were collected on ice and allowed to coagulate for $30 \mathrm{~min}$. Subsequently, serum was separated by centrifugation and frozen at $-20^{\circ} \mathrm{C}$. Ghrelin was measured with a commercially available radioimmunoassay (Phoenix Pharmaceuticals Inc., Belmont, CA, USA; intra-assay coefficient of variation (CV) $5.3 \%$; interassay CV 13.6\%). This radioimmunoassay uses ${ }^{125}$ I-labelled bioactive ghrelin as a tracer molecule and a polyclonal antibody raised in rabbits against full-length octanoylated human ghrelin. In accordance with the manual no extraction procedure was performed for the ghrelin assay. In a previous study in ten healthy volunteers, we observed mean peripheral circulating ghrelin levels of $84 \mathrm{pmol} / \mathrm{l}$ (range: 35132) (7). We used these values to compare the data of the present study.

GH was measured with a commercially available radioimmunoassay (CIS bio international, Gif-sur Yvette Cedex, France; intra-assay CV 2.8\%; interassay $4.4 \%)$.

IGF-I was measured with a commercially available immunoradiometric assay (Diagnostic Systems Laboratories Inc., Webster, TX, USA; intra-assay CV 4.9\%; interassay CV 5.1\%).

\section{Results}

\section{Baseline values}

In the control subjects, the baseline peripheral and central ghrelin levels were within the normal peripheral ghrelin concentration range, as previously reported $(7,8)$. No clear gradient could be observed between systemic and central ghrelin concentrations in the controls (Fig. 1a). In the first acromegalic subject, however, the systemic ghrelin level was well within the normal 

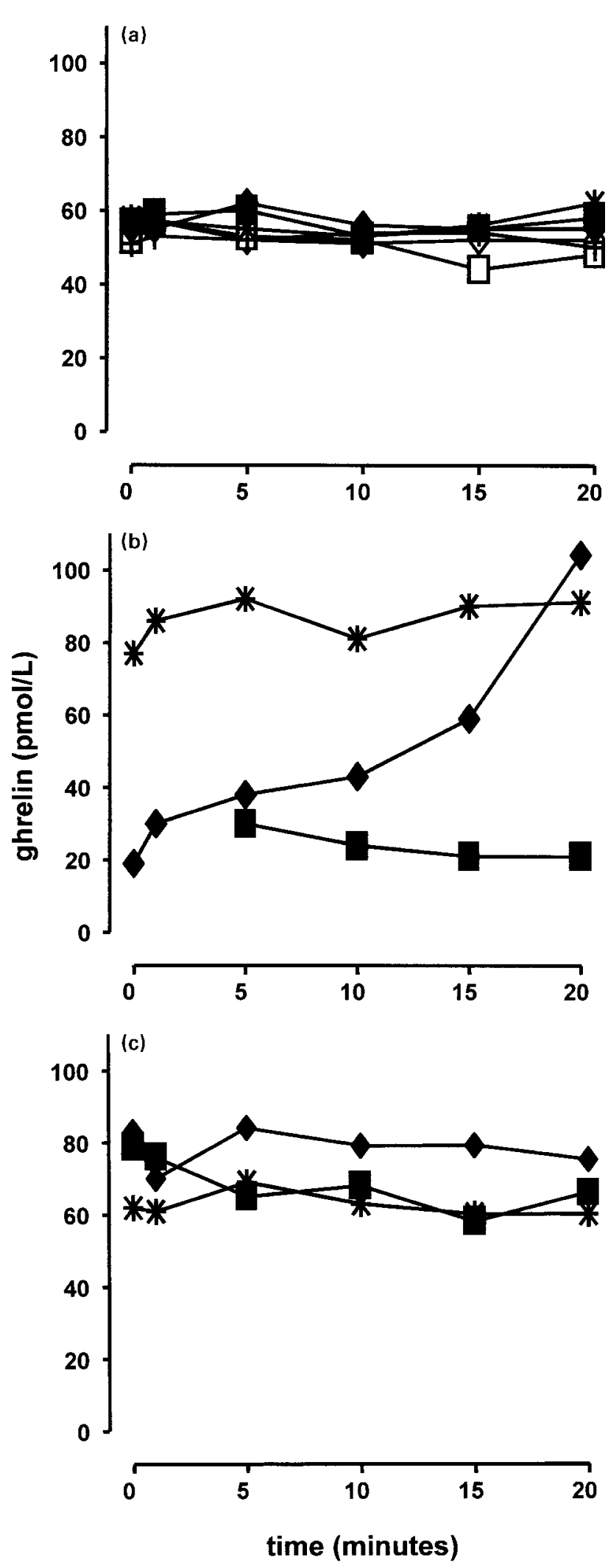

range. The central baseline ghrelin concentration in this patient was considerably lower in the right inferior petrosal vein as compared with the systemic concentration, indicating a peripheral over central gradient. The baseline sample taken from the left inferior petrosal vein had to be discarded, because of problems in the positioning of the tip of the catheter in the hypoplastic left petrosal sinus. However, repositioning enabled us to measure ghrelin in the left petrosal sinus during GHRH stimulation (Fig. 1b). In the second acromegalic patient, the baseline peripheral and central ghrelin levels were within the normal range. Also, in this acromegalic subject, no clear differences could be observed between peripheral and central ghrelin concentrations (Fig. 1c).

\section{Central and peripheral ghrelin levels after stimulation}

No change in central or peripheral ghrelin concentrations were observed after $\mathrm{CRH}$ administration in both controls (Fig. 1a). As might be expected, both controls showed a significant increase in adrenocorticotrophin (ACTH) after CRH administration in both petrosal sinuses without lateralization (data not shown).

In the first acromegalic subject, administration of GHRH induced a significant rise in ghrelin concentrations in the right inferior petrosal sinus (Fig. 1b). On this side, central ghrelin rose from $19 \mathrm{pmol} / \mathrm{l}$ at baseline to a peak level of $104 \mathrm{pmol} / \mathrm{l}, 20 \mathrm{~min}$ after GHRH administration. Concomitantly, right-sided central GH levels increased from $9 \mathrm{ng} / \mathrm{ml}$ to $746 \mathrm{ng} / \mathrm{ml}$, 20 min after stimulation (Table 1). No baseline ghrelin level in the left inferior petrosal sinus was available, because of the problems already mentioned in the positioning of the tip of the catheter. After repositioning, ghrelin levels in the left inferior petrosal sinus after GHRH stimulation showed no increase and remained about $21 \mathrm{pmol} / \mathrm{l}$. Baseline central left-sided GH levels were not available (see above). Central left-sided GH levels rose to $418 \mathrm{ng} / \mathrm{ml}$ after $\mathrm{GHRH}$ stimulation (Table 1).

Figure 1 (a) Ghrelin concentration in left ( $\square$ ) and right ( $\bullet$ ) pituitary and in systemic (peripheral) (*) blood at baseline and 1, 5, 10, 15 and 20 min after stimulation with $\mathrm{CRH}$ in control patient 1. Ghrelin concentration in left $(\square)$ and right $(\diamond)$ pituitary and in peripheral (+) blood at baseline and 1, 5, 10,15 and 20 min after stimulation with $\mathrm{CRH}$ in control patient 2. (b) Ghrelin concentration in left (ם) and right ( $\bullet$ ) pituitary and in systemic (peripheral) (*) blood at baseline and 1, 5, 10, 15 and 20 min after stimulation with GHRH in acromegalic patient 1. (c) Ghrelin concentration in left ( $\square$ ) and right $(\star)$ pituitary and in systemic (peripheral) $(*)$ blood at baseline and 1, 5, 10, 15 and 20 min after stimulation with GHRH in acromegalic patient 2 . 
Table $1 \mathrm{GH}$ levels of both acromegalics (patient 1 and patient 2) at baseline and $20 \mathrm{~min}$ after stimulation with GHRH. The GH levels were measured in a peripheral vein and in the left and right inferior petrosal sinuses.

\begin{tabular}{lcc}
\hline & $\begin{array}{c}\text { GH at baseline } \\
(\mathrm{ng} / \mathrm{ml})\end{array}$ & $\begin{array}{c}\text { GH 20 } \mathbf{m i n} \text { after stimulation } \\
(\mathrm{ng} / \mathrm{ml})\end{array}$ \\
\hline Patient 1 & & \\
$\quad$ Peripheral & 1 & 31 \\
Left & $\mathrm{NA}$ & 418 \\
Right & 9 & 746 \\
Patient 2 & & \\
Peripheral & 6 & 16 \\
Left & 233 & 228 \\
Right & 213 & 540 \\
\hline
\end{tabular}

NA, not assessed.

In the second acromegalic subject, central and peripheral ghrelin levels remained unchanged after GHRH stimulation (Fig. 1c). After GHRH administration, peripheral $\mathrm{GH}$ concentration increased from $1 \mathrm{ng} / \mathrm{ml}$ to $31 \mathrm{ng} / \mathrm{ml}$ in patient 1 and from $6 \mathrm{ng} / \mathrm{ml}$ to $16 \mathrm{ng} / \mathrm{ml}$ in patient 2 (Table 1). Peripheral ghrelin levels did not change after GHRH stimulation in these two subjects.

\section{Discussion}

Wright and co-workers (5) previously observed that systemic ghrelin levels were lower in an animal model of acromegaly. We therefore expected to find lowered systemic ghrelin levels in acromegalic subjects in whom no clear pituitary abnormalities in the MRI of the referring hospital were seen. We therefore performed BSIPSS in both subjects, at their request, to locate an adenoma. However, in the first acromegalic patient a somatotroph pituitary adenoma of $7 \mathrm{~mm}$ at the right side of the pituitary could be detected on an MRI at follow-up and, during follow-up MRI, in the second patient a centrally located somatotroph microadenoma was found with a diameter of $1 \mathrm{~cm}$.

The baseline results of our study did not show differences in systemic ghrelin levels between the two acromegalics and the obese control subjects. Although Tschöp et al. (8) have reported that systemic ghrelin levels are lower in obese versus lean subjects, our acromegalics showed even higher BMI values than the obese 'controls', which might indicate that they could serve as proper controls in this study.

Systemic ghrelin levels in the acromegalic patients were not stimulated by GHRH. Our observations suggest that systemic ghrelin levels are not clearly decreased in human acromegaly despite high systemic GH concentrations. Surprisingly, in the first acromegalic patient we observed a peripheral over central gradient of more than 1.0. The cause of this gradient of more than 1.0 is not clear. Systemic samples were drawn from the femoral vein, which is not considered to be a major source of ghrelin. In addition, an active central nervous system clearance of systemic ghrelin is not very likely. More interesting was the lateralization of pituitary ghrelin levels after GHRH stimulation in one acromegalic subject. A clear stimulation at the right side could be detected. At follow-up, an MRI revealed an ipsilateral pituitary tumor. This indicates that in this acromegalic patient no clear central overproduction of ghrelin was present and that ghrelin could still be stimulated by exogenous GHRH. In the second acromegalic patient, a centrally located somatotroph microadenoma was also found during follow-up pituitary MRI. In this patient, there was neither a gradient between baseline peripheral and central ghrelin levels nor a gradient between peripheral and central ghrelin levels after GHRH stimulation, suggesting that central ghrelin production does not substantially contribute to the systemic ghrelin level. In our normal subjects, systemic ghrelin levels also seem to be the result of peripheral ghrelin production only, as no central over peripheral gradient could be detected.

In the two healthy controls, CRH administration was not able to modify either central or systemic ghrelin levels. Ghrelin stimulates not only GH secretion, but also ACTH and prolactin secretion (2). In the two control subjects, CRH administration significantly increased both central and systemic ACTH concentrations. No direct feedback of ACTH could be found on central and systemic ghrelin levels.

In conclusion, our study suggests that, at least in some patients with active acromegaly, circulating systemic ghrelin levels are not decreased. The absence of a central over peripheral ghrelin gradient in acromegalics and controls indicates that central ghrelin production does not substantially contribute to the systemic ghrelin level.

\section{References}

1 Kojima M, Hosoda H, Date Y, Nakazato M, Matsuo H \& Kangawa K. Ghrelin is a growth hormone-releasing acylated peptide from stomach. Nature $1999 \mathbf{4 0 2}$ 656-660.

2 Arvat E, Maccario M, Di Vito L, Broglio F, Benso A, Gottero C et al. Endocrine activities of ghrelin, a natural growth hormone secretagogue (GHS), in humans: comparison and interactions with hexarelin, a nonnatural peptidyl GHS, and GH-releasing hormone. Journal of Clinical Endocrinology and Metabolism 200186 1169-1174.

3 Dieguez C \& Casanueva F. Ghrelin: a step forward in the understanding of somatotroph cell function and growth regulation. European Journal of Endocrinology 2000142 413-417.

4 Korbonits M, Bustin S, Kojima M, Jordan S, Adams E, Lowe D et al. The expression of the growth hormone secretagogue receptor ligand ghrelin in normal and abnormal human pituitary and other neuroendocrine tumors. Journal of Clinical Endocrinology and Metabolism $200186881-887$.

5 Wright C \& Bartke A. Ghrelin administration decreases insulin secretion in Ames dwarf mice. In Proceedings of the 83rd Annual Meeting of the Endocrine Society, Denver, USA, 2001. Abstract P1-P98. 
6 Miller D \& Doppman J. Petrosal sinus sampling: technique and rationale. Radiology $1991 \mathbf{1 7 8} 37-47$.

7 Janssen JAMJL, van der Toorn FM, Hofland LJ, van Koetsveld P, Broglio F, Ghigo E et al. Systemic ghrelin levels in subjects with growth hormone deficiency are not modified by one year of growth hormone replacement therapy. European Journal of Endocrinology 2001145 711-716.
8 Tschöp M, Devanarayan V, Weyer C, Tataranni PA, Ravussin E \& Heiman ML. Circulating ghrelin levels are decreased in human obesity. Diabetes 200150 707-709.

Received 13 February 2002

Accepted 15 April 2002 